\title{
Gene expression profiles in the pituitary glands of Sichuan White geese during prelaying and laying periods
}

\author{
G.L. Gao*, X.Z. Zhao*, Q. Li, J. Su and Q.G. Wang \\ Chongqing Academy of Animal Science, Chongqing, China \\ *These authors contributed equally to this study. \\ Corresponding author: Q.G. Wang \\ E-mail: wangqigui@hotmail.com
}

Genet. Mol. Res. 14 (4): 12636-12645 (2015)

Received May 9, 2015

Accepted August 25, 2015

Published October 19, 2015

DOI http://dx.doi.org/10.4238/2015.October.19.7

\begin{abstract}
To better understand the molecular mechanism(s) underlying egg-laying in Sichuan white geese, the profiles of genes in the pituitary gland were investigated during the prelaying and laying periods. Total RNA was extracted from the pituitary glands of geese during prelaying or laying periods and cDNA was generated. After sequencing and annotation, 54 upregulated and 84 downregulated genes were obtained from gene libraries. These genes were related primarily to biosynthetic processes, cellular nitrogen metabolic processes, transport, cell differentiation, cellular protein modification processes, signal transduction, and small molecule metabolic processes. Eleven genes were selected for further analyses using quantitative real-time PCR, and the results were generally consistent with the profiling results. Among these genes, levels of gonadotropin-releasing hormone, gonadotropin-inhibitory hormone, vasoactive intestinal peptide and its receptor, follistatin, estrogen receptor beta, and the progesterone receptor were differentially overexpressed during the prelaying period compared with the laying period. These results provide a solid foundation
\end{abstract}


for elucidating the molecular mechanism of egg-laying performance in Sichuan white geese.

Key words: Sichuan white geese; Pituitary gland; Prelaying; Laying; Transcriptome

\section{INTRODUCTION}

Sichuan white goose is a Chinese goose breed known for their prolific production of eggs (Pingel, 2009); however, the limitation of egg production along with poor productivity and high breeding costs has negatively affected their economic benefits and restricted their development within the goose industry (Xu et al., 2013). Thus, methods aiming to improve the reproductive performance in these geese are urgently needed.

In poultry, the pituitary is one of the most important organs for reproduction success. Reproductive hormones that are synthesized and released from the hypothalamus affect the pituitary, which in turn adjusts its secretions to maintain appropriate reproductive activity (Etches et al., 1984). For example, gonadotropin-releasing hormone (GnRH), an important and classic regulator of the hypothalamic-pituitary-gonadal (HPG) axis, is a key neurohormone involved in vertebrate reproduction that is secreted by the hypothalamus. GnRH promotes the synthesis and release of follicle-stimulating hormone (FSH) and luteinizing hormone $(\mathrm{LH})$ in the pituitary portal system (Kuo et al., 2005). These hormones then circulate in the blood and act on target organs or cells, and subsequently influence other reproductive hormones and reproduction in animals (Lee et al., 2008). Another key neurohormone in the HPG axis is gonadotropin-inhibitory hormone $(\mathrm{GnIH})$, which is a neuropeptide expressed in quail (Tsutsui et al., 2000), chicken (Ikemoto and Park, 2005), sparrow (Osugi et al., 2004), starling (Ubuka et al., 2008), zebra finch (Tobari et al., 2010), and goose. GnIH decreases gonadotropin release and synthesis via the GnRH system in birds (Tsutsui et al., 2000; Ciccone et al., 2004; Osugi et al., 2004; Bentley et al., 2006; Ubuka et al., 2006).

The breeding cycle of Sichuan white geese is divided into prelaying and laying periods, and the period during which laying ceases. Specific concentrations of plasma reproductive hormones, feed intake, and metabolic and neuroendocrine hormones correspond to each phase. For example, research has shown that the concentration of plasma prolactin (PRL), LH, progesterone (P4), and estradiol (E2) differ significantly in these periods in muscovy ducks (Li et al., 2004) and Wanxi white geese (Fang et al., 2009). Luan et al. (2013) also found differentially expressed genes for synaptotagmin-1 (SYT1), vesicle associated membrane protein 4 (VAMP4) and calmodulin binding transcription activator 1 (CAMTA1), which may be involved in the secretion of pituitary hormones during the laying period and the period of laying cessation in Huoyan geese. In addition, the expression of several genes involved in the secretion of hormones, such as $\mathrm{GnRH}, \mathrm{GnIH}$, vasoactive intestinal peptide (VIP) (He et al., 2009), and FSH $\beta$ (Run-shen et al., 2010), PRL (Wei et al., 2009), and $P R L$ receptor genes (Pan et al., 2009), differed between the prelaying and laying periods in geese. The reproductive hormones and reproduction-related genes that are altered throughout the reproductive cycle need further study.

In the present study, gene expression profiles in the pituitary glands of Sichuan white geese during the prelaying and laying periods were investigated using Illumina RNA-seq. The results provide important information to better elucidate the molecular mechanisms underlying egg-laying and to improve the egg-laying performance of Sichuan white geese. 


\section{MATERIAL AND METHODS}

\section{Ethics statement}

This study was approved by the Laboratory Animal Management Committee of Chongqing Academy of Animal Sciences and reviewed by the Ministry of Science and Technology of the People's Republic of China (approval number: 2006-398).

\section{Geese, materials, RNA extraction, and mRNA-seq library construction}

Sichuan white geese were raised in a waterfowl-breeding base in Rongchang County, Chongqing City, and kept under the same environmental conditions with free access to feed, water, and commercial corn- and soybean-based diets. Samples of pituitary tissue were collected from prelaying (180 days old) and laying ( 240 days old) ( $N=5$ each) geese, immediately frozen in liquid nitrogen, and stored at $-80^{\circ} \mathrm{C}$ for later use. Total RNA was extracted from each sample with a BIOZOL total RNA extraction kit (Bioer Technology, Hangzhou, China). Oligo(dT) beads were used to isolate poly-(A) mRNA from total RNA (Invitrogen Corporation, Carlsbad, CA, USA). Fragmented mRNA was used as a template to synthesize first-strand cDNA. Second-strand cDNA was then synthesized using buffer, dNTPs, RNase H, and DNA polymerase I (Clontech, Mountain View, CA, USA). The cDNA was purified with a QIAquick PCR extraction kit (Qiagen, Valencia, CA), following the manufacturer's protocol, and eluted with Ethidium bromide (EB) buffer for end repair and poly(A) addition. Adapters were ligated to the ends of the fragments. After purification by agarose gel electrophoresis, the fragments were enriched using PCR amplification to create a cDNA library. The cDNA library was sequenced on an Illumina sequencing platform (MiSeq) (Shanghai Personal Biotechnology Co., Ltd.).

\section{Normalized expression levels of genes from RNA-Seq and real-time PCR}

The raw reads were generated using Illumina MiSeq sequencing. After removing the adaptors and low-quality sequences with Trinity software, the clean data were mapped with the unigenes from geese pituitary tissues using MiSeq (Illumina). Reads per kilobase of exon model per million mapped reads (RPKM) (Mortazavi et al., 2008) were used to normalize the transcript abundance in samples from prelaying and laying periods to identify differentially expressed genes. HTSeq software was used to statistically analyze the expressed gene number in each sample, and then DESeq software was used to normalize the transcript abundance between samples. A 2-fold differential and a $P$ value less than 0.05 were used as criteria to identify genes differentially expressed between the two growth periods.

The differential expression of genes in pituitary tissues between the prelaying and laying periods was determined using qRT-PCR. Gene-specific primers were designed based on the gene sequences (Table 1). mRNA levels of the selected genes (CYI1, GRPP, TID, EXT2, MBPL, HBP2, CTGF, IITP2, CJLP, CA2, and GFNLI2) were detected by qRT-PCR. The reaction system was used according to the instructions provided in the SYBR Premix Ex TaqTM (Perfect Real Time) kit. Briefly, $5 \mu \mathrm{L}$ SYBR Premix Ex TaqTM (2X), $0.2 \mu \mathrm{L}$ ROX Reference Dye II (50X), $0.2 \mu \mathrm{L}$ upstream and downstream primers $(10 \mu \mathrm{M}), 1 \mu \mathrm{L}$ cDNA template, and $3.4 \mu \mathrm{L} d \mathrm{dH} 2 \mathrm{O}$ were mixed in a total volume of $10 \mu \mathrm{L}$. The mixture was added to an $\mathrm{ABI} 7500$ detection system for 40 cycles using the following reaction steps and conditions: pre-denaturation at $95^{\circ} \mathrm{C}$ for $10 \mathrm{~s}$, denaturation at $95^{\circ} \mathrm{C}$ 
for $5 \mathrm{~s}$, annealing at $60^{\circ} \mathrm{C}$, and extension for $34 \mathrm{~s}$. The melting curve was generated at $95^{\circ} \mathrm{C}$ for $15 \mathrm{~s}, 60^{\circ} \mathrm{C}$ for $10 \mathrm{~min}$, and $95^{\circ} \mathrm{C}$ for $15 \mathrm{~s}$, with triplicates run for each sample. Glyceraldehyde 3-phosphate dehydrogenase (GAPDH) was used as an internal control. The primers used for qRTPCR are listed in Table 1. All primers were synthesized by Invitrogen Biotechnology Co., Ltd.

Table 1. Gene-specific primers used for real-time polymerase chain reaction and the calculated $\mathrm{P}$ values.

\begin{tabular}{|c|c|c|c|c|}
\hline \multirow[t]{2}{*}{ Symbol } & \multirow[t]{2}{*}{ Name } & \multirow[t]{2}{*}{ Sequence } & \multicolumn{2}{|c|}{$P$ value } \\
\hline & & & RNA-seq & RT-PCR \\
\hline \multirow[t]{2}{*}{ CYI1 } & cyclin-J isoform 1 & F: 5'-GGTCTTGCTTTCCGTTGT-3' & & \\
\hline & & R: 5'-ATCTGCGAGAATCTGGTTG-3' & 0.0006 & $0.0221^{*}$ \\
\hline \multirow[t]{2}{*}{$G R P P$} & Glucose-regulated protein precursor & F: 5'-GGGGCTTGGCTTTCTTT-3' & & \\
\hline & & R: 5'-TCGGCACCACCTACTCC-3' & 0.0021 & 0.5252 \\
\hline \multirow[t]{2}{*}{$T I D$} & Type III iodothyronine deiodinase & F: 5'-CATTCACGAGCAGGTTCA-3' & & \\
\hline & & R: 5'-TGTTCAGGTTTAGCAGGAGT-3' & 0.0068 & $0.0014^{* *}$ \\
\hline \multirow[t]{2}{*}{ EXT2 } & Exostosin-2-like & F: 5'-CTGACTTACTTGCTGGTGAC-3' & & \\
\hline & & R: 5'-TGTAGAGCCTGGAGATGG-3' & 0.0001 & $0.0021^{* *}$ \\
\hline \multirow[t]{2}{*}{ MBPL } & Myelin basic protein-like & F: 5'-AAAAGCAGCAAGACTAACAC-3' & & \\
\hline & & R: 5'-GGGCATCTCGGGAAA-3' & 0.0254 & $0.0339^{*}$ \\
\hline \multirow[t]{2}{*}{ HBP2 } & Heme-binding protein 2 & F: 5'-TGTTCAGGTTTAGCAGGAGT-3' & & \\
\hline & & R: 5'-ACCGTTTCGCACCCT-3' & 0.0371 & $0.0283^{*}$ \\
\hline \multirow[t]{2}{*}{ CTGF } & Connective tissue growth factor precursor & F: 5'-GCATTAAACAAAGGCACA-3' & & \\
\hline & & R: 5'-CCTCACCCAGCAAAG-3' & 0.0045 & $0.0319^{*}$ \\
\hline \multirow[t]{2}{*}{ IITP2 } & Interferon-induced transmembrane protein 1 & F: 5'-GGACATTTGGAGGGC-3' & & \\
\hline & & R: 5'-GCTTCCGTTTGGTTT-3' & 0.0007 & $0.0451^{*}$ \\
\hline \multirow[t]{2}{*}{ CJLP } & Cyclin-J-like & F: 5'-GTGGCAACTAAAGAAGGG-3' & & \\
\hline & & R: 5'-GTGGGAAAGTCTCAAACG-3' & 0.0010 & $0.0124^{*}$ \\
\hline \multirow[t]{2}{*}{ CA2 } & Carbonic anhydrase 2 & F: 5'-CAGGGAGCCAGGGTAT-3' & & \\
\hline & & R: 5'-TTGCTGAAGCGGTGA-3' & 0.0012 & $0.0061^{* *}$ \\
\hline \multirow{2}{*}{ GFNLI2 } & Glucagon family neuropeptides-like isoform 2 & F: 5'-GCAGGCGAATGTTTACG-3' & & \\
\hline & & R: 5'-GATGGATGGAGCGAGGT-3' & 0.0016 & $0.0341^{*}$ \\
\hline \multirow[t]{2}{*}{ GAPDH } & Glyceraldehyde-3-phosphate dehydrogenase & F: 5'-AGAACATCATCCCAGCGT-3' & & \\
\hline & & R: 5'-AGCCTTCACTACCCTCTTG-3' & None & None \\
\hline
\end{tabular}

${ }^{*} \mathrm{P}<0.05 ;{ }^{* *} \mathrm{P}<0.01$.

\section{Functional annotation}

Using BLASTx (http://blast.ncbi.nlm.nih.gov/), the obtained unigenes were annotated by a series of protein databases. The databases included Non Redundant (http://www.ncbi.nlm.nih. gov/), KEGG (http://www.genome.jp/kegg/), eggNOG (http://eggnog.embl.de/), GO terms (http:// www.geneontology.org), Swiss-Prot (http://web.expasy.org/docs/swiss-prot_guideline.html), and NCBI BLAST (http://blast.ncbi.nlm.nih.gov/).

\section{RESULTS}

\section{Sequencing and assembling}

An overview of gene expression profiles in the goose pituitary gland during the prelaying and laying periods was obtained by sequencing cDNA generated for these two groups. We obtained 2,044,405,542 bp of raw data and 4,072,521 raw reads from the prelaying growth period, and $3,376,989,140 \mathrm{bp}$ of raw data and 6,727,070 raw reads from the laying growth period, with an average length of raw reads of $251 \mathrm{bp}$. After trimming and quality checking, 2,403,490,393 bp of clean data and 5,995,966 clean reads were obtained from the pituitaries of geese in the prelaying period and 1,303,441,915 bp of clean data and 3,096,833 clean reads from the laying period. The 
quality reads from the two growth periods were combined and used to determine transcriptome information from the goose pituitary samples. The total length obtained was $416,620,933 \mathrm{bp}$, with a maximum of $28,626 \mathrm{bp}$, an average of $1,021 \mathrm{bp}$, and an N50 of 2,877 bp (Table 2). We obtained 407,986 transcripts and 33,536 unigenes. The top-hit species distribution for unigene length is illustrated in Figure 1.

Table 2. Statistical analysis of goose pituitary sequencing generated using the Miseq platform.

\begin{tabular}{lcc}
\hline & Prelaying & Laying \\
\hline Raw reads & $4,072,521$ & $6,727,070$ \\
Reads length (bp) & 251 & 251 \\
Raw data (bp) & $2,044,405,542$ & $3,376,989,140$ \\
Q20 (\%) & 80.89 & 87.89 \\
Q30 (\%) & 76.27 & 84.32 \\
Gc (\%) & 43.96 & 44.23 \\
Clean reads & $5,995,966$ & $3,096,833$ \\
Clean data (bp) & $2,403,490,393$ & $1,303,441,915$ \\
Useful reads \% & 76.04 & 89.13 \\
Useful data \% & 63.76 & 71.17 \\
\hline
\end{tabular}

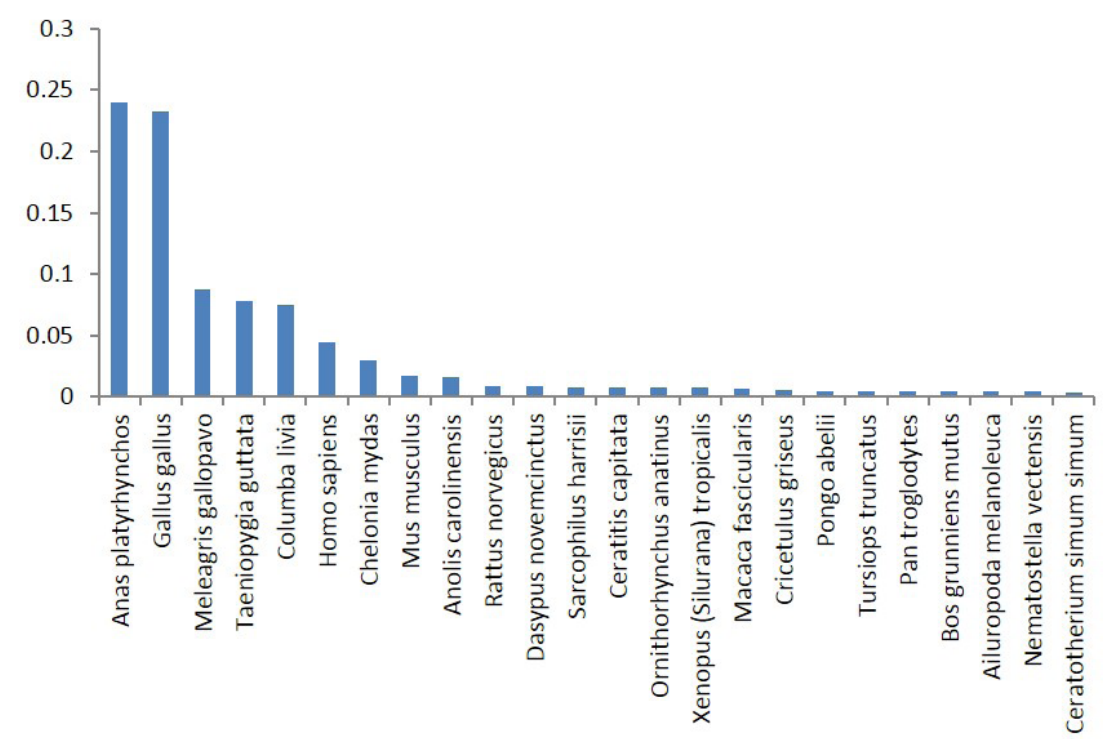

Figure 1. Top-hit species distribution.

\section{Functional annotation}

Gene ontology (GO) analysis was performed to determine the functional categories of the obtained unigenes. We found a high percentage of unigenes in the following functional categories within the main categories of biological processes and molecular and cellular components (Figure $2)$ : unfolded protein binding $(16,892$ or $7.66 \%)$, transcription factor binding $(15,126$ or $6.85 \%)$, structural molecule activity (12,901 or $5.85 \%)$, small conjugating protein binding $(13,063$ or $5.92 \%)$, and RNA binding $(11,056$ or $5.01 \%)$. 


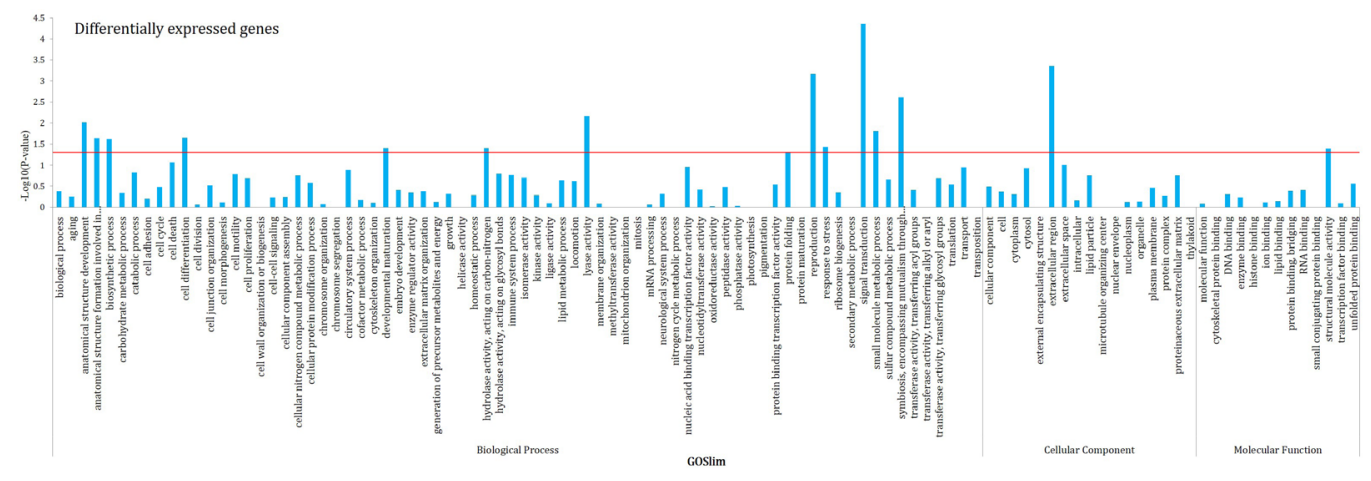

Figure 2. Gene ontology enrichment analysis.

The KEGG database was used to identify the biological pathways and functions of the pituitary genes. KEGG pathways and classifications were determined for 23,682 unigenes. The greatest numbers of unique sequences were found among infectious diseases (2616, or $7.80 \%)$, cancers $(2230,6.65 \%)$, signal transduction $(1913,5.70 \%)$, nervous system $(1523,4.54)$, and immune system $(1424,4.25 \%)$ groups (Figure 3$)$.

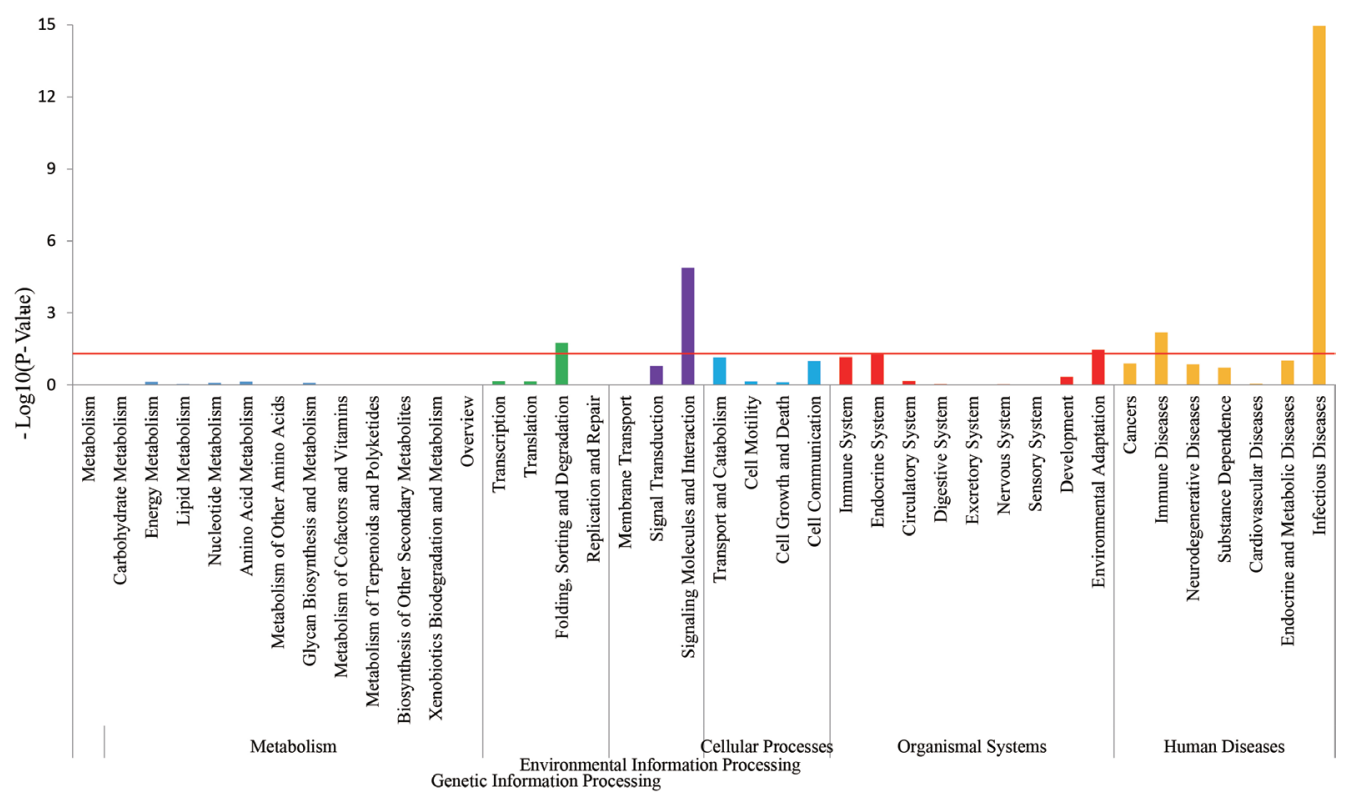

Figure 3. Functional categories of unigenes in the goose pituitary.

\section{Functional categories of differentially expressed genes}

In total, 138 genes were identified with significant differential expression: 54 genes were up-regulated 2-fold in the prelaying period, whereas 84 genes were up-regulated 2-fold during the laying period. 
A total of 104 differentially expressed genes with GO annotation were categorized as differentially expressed, and 37 of 54 that were more highly expressed in the laying period, and 67 of 84 that more highly expressed in the pre-laying period were assigned at least one GO term. The greatest number of unique sequences were found in the following groups: cell (71 or $51.45 \%$ ), intracellular (60 or $43.48 \%$ ), organelle (50 or $36.23 \%$ ), molecular function (49 or $35.51 \%$ ), and biological process (47 or $34.05 \%$ ).

Of the 72 differentially expressed genes with KEGG annotation, 23 of 54 were more highly expressed in the laying period, and 49 of 84 were more highly expressed in the pre-laying period. A high percentage of genes from the following categories was found: infectious diseases (43 or $32.09 \%$ ), signaling molecules and interaction (14 or $10.45 \%$ ), cancers (13 or $9.70 \%$ ), signal transduction (11 or $8.21 \%$ ), and immune system (10 or $7.46 \%$ ).

Seven differentially expressed genes attracted our interest, these were $G n R H, G n I H, V I P$, the VIP receptor (VIPR), follistatin (FST), estrogen receptor beta $(E R \beta)$, and the progesterone receptor $(P R)$, which are known to be important in reproductive cycle regulation and reproductive organogenesis in mammals.

\section{DISCUSSION}

In this study, Illumina sequencing technology was utilized to identify differentially expressed genes in the pituitaries of Sichuan white geese during the prelaying and laying periods. Most of the 33,536 unigenes generated BLAST hits on birds with genomes relatively similar to those in geese (Gallus gallus, 29.07\%; Anas platyrhynchos, 24.05\%; Taeniopygia guttata, 9.17\%) (Figure 1 ), which suggests that the annotation was reliable. Moreover, levels of 11 differentially expressed genes that were randomly selected were verified by qRT- PCR (Figure 4, Table 1), the results were mostly consistent with the RNA-seq. In conclusion, results obtained from RNA-seq provided a reliable basis for further studies to be developed. Interestingly, we found some reproductionrelated candidate genes that were differentially expressed in the pituitary during the two periods, such as GnRH, GnIH, VIP, VIPR, FST, ER , and PR, which might be involved in reproductive cycle regulation and reproductive organogenesis.

The GnRH system plays a key role in vertebrate reproduction, and $\mathrm{GnIH}$ decreases gonadotropin release and synthesis via the GnRH system in birds (Tsutsui et al., 2000; Ciccone et al., 2004; Osugi et al., 2004; Bentley et al., 2006; Ubuka et al., 2006). GnRH and GnIH are secreted by the hypothalamus and partially regulate the gonadotropins FSH and LH, as well as PRL (Tsutsui et al., 2012). Interestingly, the nesting behavior of poultry depends primarily on maintaining high levels of PRL (Lea et al., 1996), indicating that PRL is the key hormone responsible for inducing and maintaining nesting behavior. VIP is an important PRL-releasing factor, thus regulating PRL secretion in nesting poultry (Lea and Vowles, 1986; Opel and Proudman, 1988; El Halawani et al., 1990). FSH plays a major role in reproduction and has a multitude of effects related to development, the development and maturation of the ovary, and the stimulation of granulosa cells to increase the capacity of FSH to bind to its receptor (FSHR). FSHR levels increase until the ovary matures, and this process is under the control of the GnRH system. FST suppresses pituitary FSH release and plays an auxiliary role in regulating reproduction in adult animals (Robertson et al., 1987; Ueno et al., 1987; Ying, 1988). Estrogens and progesterone also participate in the negative feedback of the GnRH system in the central nervous system (Sisk and Foster, 2004) Estrogens play a key role in maintaining tissue homeostasis in pituitary function, regulating LH secretion via the MAPK signal pathway (Iqbal et al., 2009), and negatively regulating the synthesis and secretion of FSH by 
suppressing the expression of pituitary activin (Bilezikjian et al., 2006), inhibiting LH secretion from the pituitary (Zhou et al., 2001), and inducing PRL gene expression through activated estrogen receptors (ERs) (Freeman et al., 2000). The biological functions of estrogens are mediated by ERs, making ER an important part of the reproductive system of poultry. Progesterone plays an important role in mammary gland development and reproductive behavior and is involved in neuroprotection, myelination, and some aspects of the inflammatory response (Mani and O'Malley, 2002; Blaustein, 2008; De Nicola et al., 2009).

In the present study, we found that the genes encoding $\mathrm{GnRH}, \mathrm{GnIH}, \mathrm{VIP}, \mathrm{VIPR}, \mathrm{FST}, \mathrm{ER} \beta$, and PR were differentially expressed during the two growth periods, suggesting that these seven genes are involved in the regulation of reproductive hormones in the pituitary, particularly $\mathrm{GnRH}$ and $\mathrm{GnIH}$, which play an important role in the stimulation and release of pituitary reproductive hormones. The function of these genes needs further study, which could provide great value to our understanding of the reproductive biology of geese.

In conclusion, in this study, 33,536 unigenes were obtained from the pituitaries of Sichuan white geese during the laying and prelaying periods. We found that 54 genes were up-regulated in the prelaying period, and 84 genes were up-regulated 2-fold during the laying period. We also determined that seven candidate reproductive genes of interest were differentially expressed in the pituitary during prelaying and laying periods.

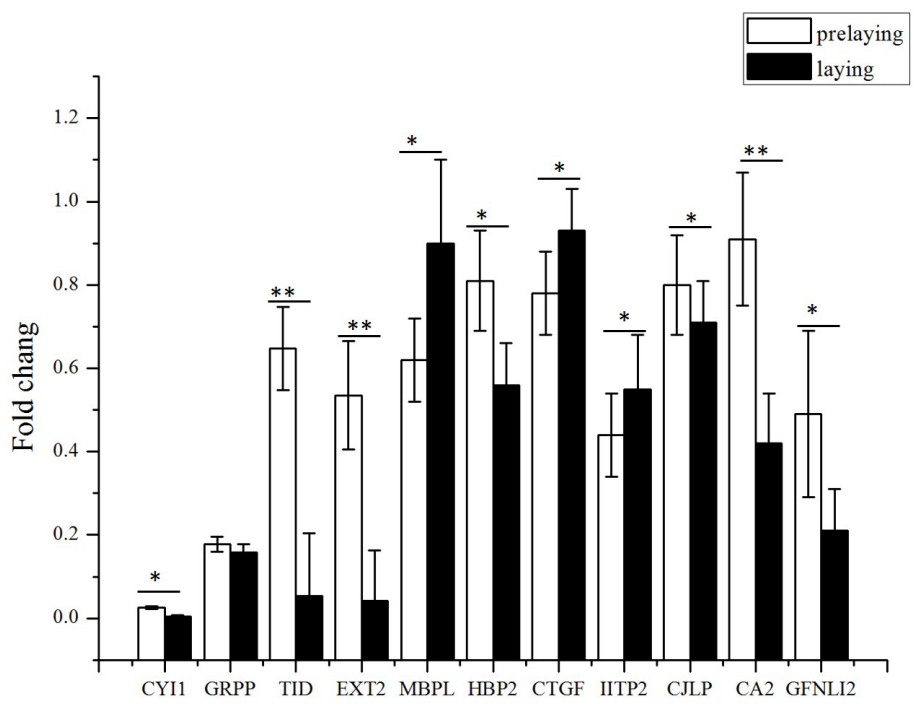

Figure 4. Real-time polymerase chain reaction validation of the differentially expressed transcripts.

\section{Conflicts of interest}

The authors declare no conflict of interest.

\section{ACKNOWLEDGMENTS}

The authors would like to acknowledge the members of the Poultry Science Institute of Chongqing Academy of Animal Science for managing the birds and collecting data, and the work 
of Shanghai Personal Biotechnology Co., Ltd. in sequencing and data analysis. This research was supported by the Application Development projects of Chongqing Science and Technology (\#cstc2013yykfC80003); Chongqing Agricultural Development Foundation (\#14416); and Chongqing Fundamental Research Funds Projects (\#13428).

\section{REFERENCES}

Bentley GE, Jensen JP, Kaur GJ, Wacker DW, et al. (2006). Rapid inhibition of female sexual behavior by gonadotropininhibitory hormone (GnlH). Horm. Behav. 49: 550-555.

Bilezikjian LM, Blount AL, Donaldson CJ and Vale WW (2006). Pituitary actions of ligands of the TGF- $\beta$ family: activins and inhibins. Reproduction 132: 207-215.

Blaustein JD (2008). Feminine reproductive behavior and physiology in rodents. In: Hormones, brain, and behavior (2nd edition), (Pfaff DW, Arnold AP, Etgen AM, Fahrbach SE and Rubin RT, eds), 2009, Elsevier: San Diego, 67-107.

Ciccone NA, Dunn IC, Boswell T, Tsutsui K, et al. (2004). Gonadotrophin inhibitory hormone depresses gonadotrophin alpha and follicle-stimulating hormone beta subunit expression in the pituitary of the domestic chicken. J. Neuroendocrinol. 16: 999-1006.

De Nicola AF, Labombarda F, Gonzalez Deniselle MG, Gonzalez SL et al. (2009). Progesterone neuroprotection in traumatic CNS injury and motoneuron degeneration. Front. Neuroendocrinol. 30: 173-187.

El Halawani ME, Silsby JL and Mauro LJ. (1990). Vasoactive intestinal peptide is a hypothalamic prolactin-releasing neuropeptide in the turkey (Meleagris gallopavo). Gen. Comp. Endocrinol. 78: 66-73.

Etches RJ, Petitte JN and Anderson Langmuir CE. (1984). Interrelationships between the hypothalamus, pituitary gland, ovary, adrenal gland, and the open period for LH release in the hen (Gallus domesticus). J. Exp. Zool. 232: 501-511.

Fang DA, Geng ZY, Luo ZH, et al. (2009). Research on change pattern pf PRL, E2, P4 and LH in Wan-xi White Goose reproduction cycle. J. Shangrao Normal Univer. 29: 71-76.

Freeman ME, Kanyicska B, Lerant, A and Nagy G (2000). Prolactin: structure, function, and regulation of secretion. Physiol. Rev. 80: 1523-1631.

Ikemoto T and Park MK (2005). Chicken RFamide-related peptide (GnlH) and two distinct receptor subtypes: identification, molecular characterization, and evolutionary considerations. J. Reprod. Dev. 51: 359-377.

Iqbal J, Latchoumanin O, Sari IP, Lang RJ, et al. (2009). Estradiol-17beta inhibits gonadotropin-releasing hormone-induced $\mathrm{Ca} 2+$ in gonadotropes to regulate negative feedback on luteinizing hormone release. Endocrinologyz 150: $4213-4220$.

Kuo YM, Shiue YL, Chen CF, Tang PC, et al. (2005). Proteomic analysis of hypothalamic proteins of high and low egg production strains of chickens. Theriogenology 64: 1490-1502.

Lea R and Vowles D (1986). Vasoactive intestinal polypeptide stimulates prolactin release in vivo in the ring dove (Streptopelia risoria). Experientia 42: 420-422.

Lee VH, Lee LT and Chow BK (2008). Gonadotropin-releasing hormone: regulation of the GnRH gene. FEBS J. 275: 54585478.

Li A, Wang H, Zhu MX, Wang SK, et al. (2004). The Chang Regularity of the Concentration of Reproductive Hormone during the Broody Period in Muscovy Ducks. Acta Vet. Zootec. Sin. 35: 522-525.

Luan X, Cao Z, Xu W, Gao M, et al. (2013). Gene expression profiling in the pituitary gland of laying period and ceased period Huoyan geese. Asian-Australas. J. Anim. Sci. 85: 650-659.

Mani S and O'Malley B. (2002). Mechanism of progesterone receptor action in the brain. In: Hormones, brain and behavior (Pfaff D, eds). Academic Press, New York, 643-682.

Mortazavi A, Williams BA, McCue K, Schaeffer L, et al. (2008). Mapping and quantifying mammalian transcriptomes by RNASeq. Nat. Methods 5: 621-628.

Opel $\mathrm{H}$ and Proudman $\mathrm{J}$ (1988). Stimulation of prolactin release in turkeys by vasoactive intestinal peptide. Exp. Biol. Med. 187: 455-460.

Osugi T, Ukena K, Bentley GE, O’Brien S, et al. (2004). Gonadotropin-inhibitory hormone in Gambel's white-crowned sparrow (Zonotrichia leucophrys gambelii): cDNA identification, transcript localization and functional effects in laboratory and field experiments. J. Endocrinol. 182: 33-42.

Pan Zhu (2009). mRNA exprseeion profile of PRLR gene in reproductive cycle in geese. Anhui Agric. Univ. Master Degree Dissert.

Pingel H (2009). Waterfowl production for food security. In: Conference at the 4th World Waterfowl conference, Thrissur, India

Robertson DM, Klein R, De Vos FL, McLachlan RI, et al. (1987). The isolation of polypeptides with FSH suppressing activity from bovine follicular fluid which are structurally different to inhibin. Biochem. Biophys. Res. Commun. 149: $744-749$. 
Run SJ, Xiao DU, Xing YC, Geng ZY, et al. (2010). Expression of pituitary FSH $\beta$ mRNA during reproduction cycle in Wanxi white goose. J. China Agric. Univ. 6: 021.

Sisk CL and Foster DL (2004). The neural basis of puberty and adolescence. Nat. Neurosci. 7: 1040-1047.

Tobari Y, lijima N, Tsunekawa K, Osugi T, et al. (2010). Identification of gonadotropin-inhibitory hormone in the zebra finch (Taeniopygia guttata): Peptide isolation, cDNA cloning and brain distribution. Peptides 31: 816-826.

Tsutsui K, Saigoh E, Ukena K, Teranishi H, et al. (2000). A novel avian hypothalamic peptide inhibiting gonadotropin release. Biochem. Biophys. Res. Commun. 275: 661-667.

Tsutsui K, Ubuka T, Bentley GE and Kriegsfeld LJ (2012). Gonadotropin-inhibitory hormone (GnlH): discovery, progress and prospect. Gen. Comp. Endocrinol. 177: 305-314.

Ubuka T, Kim S, Huang YC, Reid J, et al. (2008). Gonadotropin-inhibitory hormone neurons interact directly with gonadotropinreleasing hormone-l and-II neurons in European starling brain. Endocrinology 149: 268-278.

Ubuka T, Ukena K, Sharp PJ, Bentley GE, et al. (2006). Gonadotropin-inhibitory hormone inhibits gonadal development and maintenance by decreasing gonadotropin synthesis and release in male quail. Endocrinology 147: 1187-1194.

Ueno N, Ling N, Ying SY, Esch F, et al. (1987). Isolation and partial characterization of follistatin: a single-chain Mr 35,000 monomeric protein that inhibits the release of follicle-stimulating hormone. Proc. Natl. Acad. Sci. 84: 8282-8286.

Xu Q, Zhao W, Chen Y, Tong Y, et al. (2013). Transcriptome profiling of the goose (Anser cygnoides) ovaries identify laying and broodiness phenotypes. PloS one 8: e55496.

Ying SY (1988). Inhibins, activins, and follistatins: gonadal proteins modulating the secretion of follicle-stimulating hormone. Endocr. Rev. 9: 267-293.

Zhou SK, Ren HM, Wang J, Zhao W, et al. (2001). Effects of Estrogen and/or Progesterone on Morphology of Pituitary Luteinizing Hormone Cells. Reprod. Contracept. 21: 269-276. 